\title{
Perception Regarding Oral Health Among Patients Visiting Dental Outpatient Department
}

Saima Asim, Syed Muhammad Zulfiqar Hyder Naqvi, Syed Imtiaz Ahmed Jafry, Shikoh Naz ABSTRACT:

Objective: To assess knowledge, attitude and practice regarding oral health among patients visiting dental OPD in hospitals of district Malir, Karachi.

Study Design and Setting: A cross-sectional study was conducted at dental outpatient departments of two hospitals of district Malir, Karachi.

Methodology: A total of 393 participants were randomly interviewed by the principal investigator with the help of structured questionnaire developed specifically for the study after obtaining written informed consent over the study of 6 months. Data was entered and analyzed in SPSS version 21. Inferential analysis was performed using chi-square test whereas binary logistic regression was used to develop a risk assessment model for the study outcome. The significance level was set at 0.05 .

Results: Overall $31.8 \%$ of the study participants had adequate knowledge, $25.2 \%$ had adequate attitude whereas $32.2 \%$ had adequate practices with regards to oral health. Furthermore, multivariable analysis revealed that higher qualification of the study participants had significant positive associations with adequateness of all of the knowledge, attitude and practices of the study participants regarding oral health at $\mathrm{p}$-value of $<0.05$.

Conclusion: The level of knowledge and appropriateness of attitude and practices of the study participants was less than satisfactory. The higher education level had a positive impact over the oral health of the participants. It is recommended that healthcare providers and government, in their respective capacities, educate and persuade people to take better care of their oral health.

Key words: Attitude, Knowledge, Oral Health, Outpatients

INTRODUCTION:

Oral health is essential to general health and quality of life. According to World Health Organization "it is a state of being free from mouth and facial pain, oral and throat cancer, oral infections and sores, periodontal disease, tooth decay, tooth loss and other diseases and disorders that limit an individual capacity in biting, chewing, smiling, speaking, and psychosocial well-being.",

Oral health is considered a fundamental to general health, but it is often taken for granted. Mouth is like a window into the health of body. Oral health can reveal signs of nutritional deficiencies or general infections and many systemic diseases show oral manifestations. Oral diseases

\begin{tabular}{l} 
I Saima Asim \\
I Lecturer \\
I Email: saimaasim966@ gmail.com \\
I Syed Muhammad Zulfiqar Hyder Naqvi \\
I Assistant Professor \\
I Baqai Medical University Karachi \\
I Syed Imtiaz Ahmed Jafry \\
I Associate Professor \\
I Baqai Medical University Karachi \\
I Shikoh Naz \\
I Hamdard University Dental Hospital \\
I Received: 12-03-2019 \\
I Accepted: 04-09-2019 \\
\hline- I
\end{tabular}

and non-communicable diseases are found to be closely interlinked by sharing common risk factors such as excess sugar intake and tobacco use and underlying inflammatory pathways. $^{2,3}$

The most common oral diseases are dental caries, periodontal diseases, oral cancer, oral infectious disease, trauma from injuries and hereditary lesions. Dental caries involves the softening of hard tooth tissues and proceeding to the formation of a cavity, nearly $100 \%$ of adults have dental cavities. ${ }^{1}$ It is a disease with considerable economic and quality-of-life burdens ${ }^{4}$, and can be arrested and prevented by using constant low level fluoride in mouth. ${ }^{5}$

Tooth loss can be due to caries, eruption problems, and periodontal diseases. ${ }^{6}$ Due to poor oral hygiene, plaque can build up along gum lines which lead to many diseases like gingivitis, periodontitis. Long term gum infections and periodontitis leads to detachment of supporting structures from the teeth and eventual tooth loss. Diseases commonly related to tooth loss include cardiovascular disease ${ }^{7}$ cancer, ${ }^{8}$ osteoporosis, ${ }^{9}$ and diabetes mellitus. ${ }^{10}$ Therefore it is important to not only maintain good oral hygiene but also overall good health. ${ }^{7}$

The burden of oral diseases is higher among poor and disadvantaged population group and is also dependent upon the geographical area and services provided to community. ${ }^{1}$ Globally about $30 \%$ of persons aged $60-74$ have no natural teeth. ${ }^{1}$ In 2010 , it was estimated that untreated caries in 
permanent teeth was the most prevalent condition globally, with 2.4 billion people affected, while untreated caries in deciduous teeth was the 10th-most prevalent condition globally, with 621 million children affected. ${ }^{11}$ It has also been estimated that severe periodontitis affects approximately $10 \%$ of the global population. ${ }^{12}$ Moreover, oral cancers are more common in people over 40 , particularly men. It has been estimated that half a million cases of oral cancer are currently present around the globe with the trends rising in the young individuals particularly. ${ }^{13,14}$ Traditional habits in some cultures for instance, chewing tobacco, betel quid, gutka and paan are significantly dangerous. Dental trauma is another major health problem in children and adolescents and its incidence has been reported to peak at 9 years of age. ${ }^{15}$ It is more frequently observed in males as compared to females with falling, fight, sports, accidents, and hitting objects are among common causative factors. ${ }^{16}$

Due to lack of public health programs and shortage of dentists in low and middle income countries, oral diseases are dramatically increasing; though they are on the rise even in high income countries but the causes and risk factors are different. In developing societies people are not aware of the importance of regular dental check-ups and believes that they need to see a dentist only if they are in pain. One can practice good oral hygiene by brushing teeth twice a day with fluoride tooth paste, cleaning between teeth once a day with floss or another interdental cleaner, replacing your tooth brush every 3 or 4 months and by eating a balance diet and limiting between snacks.

Therefore it is imperative that dental patients should have adequate awareness, attitude and practices regarding oral health, but to the best of authors' knowledge, the available local data is scarce. ${ }^{17-19}$ This study was therefore conducted to assess knowledge, attitude and practice regarding oral health among patients visiting dental OPD in hospitals of district Malir, Karachi.

\section{METHODOLOGY:}

This cross sectional study was conducted after getting ethical approval of Baqai Institute of Health Sciences. The study was conducted among 393 conveniently sampled patients from two randomly selected hospitals of District Malir, Karachi for the period of six months. Using 50\% prevalence of related knowledge, attitude and practices with $95 \%$ confidence interval and $5 \%$ precision the calculated sample size was 385 patients. The study population consisted of dental patients of either gender aged 18 years and above visiting government and private hospitals in District Malir, Karachi. Patients with serious illness and disabled patients were excluded from the study. After getting written informed consent patients were interviewed by the principal investigator with the help of a structured questionnaire developed specifically for the study. The questionnaire was pre-tested on 5\% of the sample size to check for face validity and internal reliability and was modified accordingly to yield a Cronbach's alpha value of 0.755 . The questionnaire contained questions about demographic characteristics, knowledge, attitude and practice regarding oral health of the participants. Once the data were collected and entered in SPSS version 21 , knowledge, attitude and practice scores of the study participants were calculated separately by giving a score of 1 to a correct response and 0 to an incorrect response. These scores were then used to classify knowledge, attitude and practice of each participant as either adequate if they were above the selected cut off $70 \%$ or inadequate if they were not.Multivariable analysis using binary logistic regression was done to develop risk assessment models for the outcome variables while controlling for the potential effects of confounding variables. The significance level was set at 0.05 . Those participants who were found to have inadequate knowledge, attitude or practice regarding oral health were given necessary awareness at the completion of the interview.

\section{RESULTS:}

A total of 393 participants were included in the study with the response rate of $100 \%$. The study results revealed that the mean age of the study participants was $38.29 \pm 13.20$ years, $\mathrm{n}=230(58.5 \%)$ of them were males, $\mathrm{n}=261(66.4 \%)$ were married, $\mathrm{n}=238(60.6 \%)$ lived in joint family system, $\mathrm{n}=233(59.3 \%)$ were urdu speaking, only $\mathrm{n}=112(28.5 \%)$ were graduates or had higher education whereas $n=244$ (62.1\%) had monthly income between 15000 to 75000 rupees.

The study results showed that overall $31.8 \%$ participants had adequate knowledge, $25.2 \%$ had adequate attitude whereas $32.2 \%$ of them had adequate practices with regard to oral health (Figure 1).

The logistic regression model revealed that after controlling for all other demographic variables only family system, qualification and monthly household income had significant associations with adequateness of knowledge where those who lived in joint family system had lesser odds of having adequate knowledge than those who lived in nuclear family system (AOR=0.578, $\mathrm{p}=0.024$ ); those who were able to read and write, were intermediate or graduate or above had greater odds of having adequate knowledge than those who were illiterate $(\mathrm{AOR}=10.867, \mathrm{p}=0.033, \mathrm{AOR}=8.195, \mathrm{p}=0.044$ and $\mathrm{AOR}=19.791, \mathrm{p}=0.005$ respectively) and those who had monthly household income between 15000-75000 or 76000 and above had greater odds of having adequate knowledge than those who had monthly household income of less than $15000(\mathrm{AOR}=2.013, \mathrm{p}=0.014$ and $\mathrm{AOR}=4.911, \mathrm{p}=0.007$ respectively)-Table 1.

The logistic regression model revealed that after controlling for all other demographic variables only mother tongue and qualification had significant associations with adequateness of attitude where those who were Sindhi speaking had greater odds of having adequate attitude than those who were Urdu 
Figure 1: Adequateness of knowledge, attitude and practice

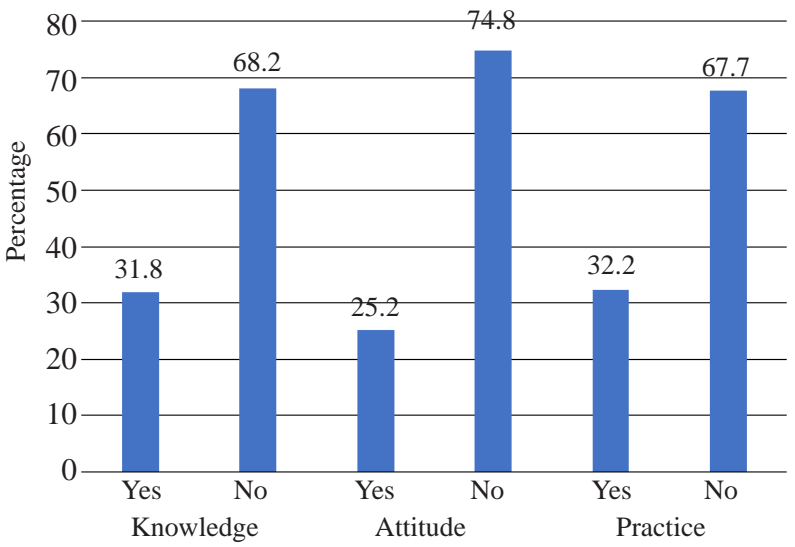

speaking $(\mathrm{AOR}=2.284, \mathrm{p}=0.022)$ and those who were graduate or above had greater odds of having adequate attitude than those who were illiterate $(A O R=15.901$, $\mathrm{p}=0.008)$-Table 2 .

The logistic regression model revealed that after controlling for all other demographic variables only gender, qualification and monthly household income had significant associations with adequateness of practice where females had greater odds of having adequate practice than males $(\mathrm{AOR}=2.515$, $\mathrm{p}<0.001)$; those who had secondary education and were intermediate or graduate had greater odds of having adequate practice than those who were illiterate $(A O R=5.262, \mathrm{p}=0.037$, $\mathrm{AOR}=8.36, \mathrm{p}=0.006, \mathrm{AOR}=8.837, \mathrm{p}=0.006$, respectively); than those who had monthly household income 76000 and above had greater odds of having adequate practice than

Table 1: Adjusted Associations between demographic Characteristics and Adequateness of Knowledge

\begin{tabular}{|c|c|c|c|c|c|}
\hline \multirow{2}{*}{\multicolumn{2}{|c|}{ Variables $(n=393)$}} & \multirow{3}{*}{$\begin{array}{c}\text { AOR } \\
0.578\end{array}$} & \multicolumn{2}{|c|}{ 95\% C.I. } & \multirow{3}{*}{$\begin{array}{c}\mathrm{P} \\
0.024 \\
\end{array}$} \\
\hline & & & \multirow{2}{*}{$\begin{array}{c}\text { Lower } \\
0.359\end{array}$} & \multirow{2}{*}{$\begin{array}{c}\text { Upper } \\
0.93 \\
\end{array}$} & \\
\hline Family System & Joint & & & & \\
\hline \multirow{5}{*}{ Educational Status } & Able to read and write & 10.867 & 1.219 & 96.894 & 0.033 \\
\hline & Primary & 1.817 & 0.153 & 21.581 & 0.636 \\
\hline & Secondary & 4.421 & 0.534 & 36.627 & 0.168 \\
\hline & Intermediate & 8.195 & 1.054 & 63.718 & 0.044 \\
\hline & Graduate and above & 19.791 & 2.514 & 155.812 & 0.005 \\
\hline \multirow{2}{*}{ Monthly Household Income } & $15000-75000$ & 2.013 & 1.029 & 3.939 & 0.014 \\
\hline & 76000 and above & 4.911 & 1.552 & 15.536 & 0.007 \\
\hline
\end{tabular}

Table 2: Adjusted Associations between Demographic Characteristics and Adequateness of Attitude

\begin{tabular}{|c|c|c|c|c|c|}
\hline \multirow{2}{*}{\multicolumn{2}{|c|}{ Variables $(n=393)$}} & \multirow{3}{*}{$\begin{array}{l}\text { AOR } \\
2.284\end{array}$} & \multicolumn{2}{|c|}{$95 \%$ C.I. } & \multirow{3}{*}{$\begin{array}{c}\mathrm{P} \\
0.022\end{array}$} \\
\hline & & & \multirow{2}{*}{$\begin{array}{c}\text { Lower } \\
1.127 \\
\end{array}$} & \multirow{2}{*}{$\begin{array}{l}\text { Upper } \\
4.628 \\
\end{array}$} & \\
\hline \multirow{3}{*}{ Mother Tongue } & Sindhi & & & & \\
\hline & Punjabi & 1.806 & 0.942 & 3.462 & 0.075 \\
\hline & Seraiki/Balochi & 2.09 & 0.989 & 4.417 & 0.054 \\
\hline \multirow{5}{*}{ Educational Status } & Able to read and write & 8.111 & 0.926 & 71.063 & 0.059 \\
\hline & Primary & 1.44 & 0.121 & 17.112 & 0.773 \\
\hline & \begin{tabular}{|l|} 
Secondary \\
\end{tabular} & 7.27 & 0.902 & 58.595 & 0.062 \\
\hline & Intermediate & 6.998 & 0.899 & 54.5 & 0.063 \\
\hline & Graduation and above & 15.901 & 2.053 & 123.165 & 0.008 \\
\hline
\end{tabular}

Table 3: Adjusted Associations between Demographic Characteristics and Adequateness of Practice

\begin{tabular}{|c|c|c|c|c|c|}
\hline \multirow{2}{*}{\multicolumn{2}{|c|}{ Variables $(n=393)$}} & \multirow{3}{*}{$\begin{array}{c}\text { AOR } \\
2.515\end{array}$} & \multicolumn{2}{|c|}{ 95\% C.I. } & \multirow{3}{*}{$\begin{array}{c}\mathrm{P} \\
<0.001 \\
\end{array}$} \\
\hline & & & \multirow{2}{*}{$\frac{\text { Lower }}{1.576}$} & \multirow{2}{*}{\begin{tabular}{|l|} 
Upper \\
4.015 \\
\end{tabular}} & \\
\hline Gender & Female & & & & \\
\hline \multirow{5}{*}{ Educational Status } & Able to read and write & 1.529 & 0.229 & 10.191 & 0.661 \\
\hline & Primary & 3.283 & 0.563 & 19.156 & 0.186 \\
\hline & Secondary & 5.262 & 1.107 & 25.016 & 0.037 \\
\hline & Intermediate & 8.36 & 1.836 & 38.069 & 0.006 \\
\hline & Graduate and above & 8.837 & 1.871 & 41.737 & 0.006 \\
\hline \multirow{2}{*}{ Monthly Household Income } & $15000-75000$ & 1.227 & 0.679 & 2.22 & 0.498 \\
\hline & 76000 and above & 3.624 & 1.241 & 10.581 & 0.018 \\
\hline
\end{tabular}


those who had monthly household income of less than 15000 (AOR=3.624, $\mathrm{p}=0.018)$ - Table 3 .

\section{DISCUSSION:}

The study findings revealed that $72.2 \%$ of the study participants correctly knew about the relationship between oral health and systemic well-being. Similarly, Nagarajappa $\mathrm{R}$ et al., in 2015 reported that $64.5 \%$ of the participants correctly knew about the relationship between oral health with systemic illness. ${ }^{20}$ Likewise, Singh A et al., in 2014 also reported that $68 \%$ subjects were aware that dental health has an effect on general health. ${ }^{21}$

Regarding impact of regular tooth brushing on teeth $87 \%$ of the participants were found to have accurate knowledge in our study whereas Khan F et al., in 2013 reported that $58 \%$ of the participants correctly knew about the significance of tooth brushing. ${ }^{17}$ This difference in findings could be due to difference in study populations and to the smaller sample size of the later study.

With regards to using different types of cleaning methods, $60.3 \%$ of the participants correctly knew about other oral cleaning aids than brushing whereas Kaira LS et al., in 2012 reported that only $30 \%$ of the participants had accurate knowledge regarding other oral hygiene aids. ${ }^{22}$ This difference in finding can be attributed to different characteristics of the study populations as the later study was conducted on nurses.

In our Study; $86.2 \%$ of the study participants correctly knew that smoking, betal nut chewing, paan and gutka cause oral cancer. Similarly Kaira LS et al., in 2012 reported 95\% of the participants were known about harmful effects of tobacco and its products. ${ }^{22}$ Interestingly, this repeated finding shows a good level of awareness among the study participants about the harmful effects of commonly used addictive substances on oral health.

Our study revealed that $78.6 \%$ of the participants were found to have correct knowledge that consumption of sugary foods and drinks causes tooth decay. Khan F et al., in 2013 reported that $90 \%$ of the study participants correctly knew that sugar promotes tooth decay ${ }^{17}$ whereas Dawani N et al., in 2013 reported that $74 \%$ of the subjects were interviewed and identified sugar as an etiological factor for caries. ${ }^{23}$

In our study $57 \%$ of the participants knew that bleeding gums is a disease and needs consultation of a dentist. But contrary to these findings, Dawani $\mathrm{N}$ et al., in 2013 reported that only $7 \%$ of participants were aware of gum diseases. ${ }^{23}$ This difference in finding can be attributed to different study populations as the later study was conducted in school teachers. The $45.3 \%$ of the study participants thought that it was necessary to visit dentist every 6 months for regular dental checkup. Kapoor D et al., in 2014 reported that only $9.3 \%$ of patients interviewed felt the need to visit the dentist on regular basis i.e. once in 6 months. ${ }^{43}$ This difference in finding in study can be attributed to the difference in population characteristics as the later study was conducted in India.

Regarding frequency of brushing teeth, $42.8 \%$ of study participants were found to brush their teeth more than once a day. Similarly another study reported that $51.3 \%$ and $50 \%$ of the study participants respectively brushed their teeth twice a day. ${ }^{17,18}$ But literature reports contrary findings as well. Nagarajappa R et al., in 2015 and Kapoor D et al., in 2014 reported that only $23 \%$ and $18.5 \%$ of the study participants respectively brushed their teeth twice a day. ${ }^{20,24}$ These mix findings might be due to different methodological approaches of the aforementioned studies. Nevertheless, it is intriguing to observe such differences in reported findings.

Only $13.2 \%$ of the study participants were found to have correct practice regarding time spent on brushing teeth whereas Nagarajappa R et al., in 2015 reported that $41.5 \%$ of study participants had correct practice regarding time spent on brushing teeth. ${ }^{20}$ This difference in finding could be due to the difference in population characteristics because both studies were conducted in different countries.

Moreover, $67.2 \%$ of the respondents replied that they never smoke. Likewise Khan F et al., in 2013 reported that 70\% of respondents were not smoking. ${ }^{17}$

In our study; $80.9 \%$ of the study participants used tooth paste to clean their teeth and these results were analogous with another study in which $90 \%$ of the respondents used tooth paste and tooth brush as tooth cleaning aid. ${ }^{18}$ Kapoor D et al., in 2014 were reported that $92.2 \%$ of the male while $87.6 \%$ of the female respondents preferred tooth brushing with tooth paste. ${ }^{24}$ Likewise Kaira LS et al., in 2012 reported 70\% whereas Verma S et al., in 2019 found almost 60\% of the participants were using tooth paste with tooth brush, a recommended oral hygiene practice. ${ }^{22,}{ }^{25}$ Goryawala SN et al., in 2016 also reported $92.2 \%$ of the patients were using some type of tooth paste for oral hygiene maintenance. ${ }^{26}$

In the following study; $49.9 \%$ of the participants were changed the tooth brush within 3 months and these results were corresponding with the results of Younus A \& Qureshi A in 2016 in which $65.5 \%$ of participants change their tooth brush every 3 months. ${ }^{17}$ Unlike these results, Ahmed ZUet al., in 2016 reported that $4.5 \%$ of the male while $6.31 \%$ of the female participants changed their tooth brush within 3 months. ${ }^{18}$ These different finding of the later study can be attributed to lower socioeconomic status of that study's population.

Furthermore, with regard to the study findings about standard brushing technique, whether professional cleaning of teeth weaken tooth structure, harmful effects of boring water on teeth, importance of brushing teeth after every meal, significance of fillings of decayed teeth, frequency of consuming paan and visiting dentist in case of dental pain, a comparison could not be made with the published literature as a thorough search did not reveal any relevant published 
data. It is acknowledged that being a cross-sectional study, the study results might have suffered from limitation in recall. Moreover, the use of convenience sampling technique might have affected the generalizability of the study results.

It is recommended that people should be made aware of oral health related adequate knowledge, attitude and practices by all stakeholders, especially by healthcare providers, that will help them to lead a healthy and longer life. Furthermore, more efforts are required for the awareness campaign in public and private sectors to take better care of oral health of masses.

\section{CONCLUSION:}

The level of knowledge and appropriateness of attitude and practices of the study participants with regard to oral health was less than satisfactory. Furthermore, higher qualification of the study participants was positively associated with adequateness of all of their knowledge, attitude and practices regarding oral health

\section{REFERENCES:}

1. Oral Health. WHO; 2012 [cited 2018 20th February]; Available from: www.who.int/mediacentre/factsheets/fs318/en/.

2. Jin LJ, Lamster IB, Greenspan JS, Pitts NB, Scully C, Warnakulasuriya S. Global burden of oral diseases: emerging concepts, management and interplay with systemic health. Oral Dis. 2016; 22(7):609

3. Bana KM, Ahmad F, Danish SH, Bana NF, Kazmi AR. Non communicable diseases and oral health: Introspection. Pak J Med Dent. 2016;5(2):38-44

4. Pitts NB, Zero DT, Marsh PD, Ekstrand K, Weintraub JA, Ramos-Gomez F, Tagami J, Twetman S, Tsakos G, Ismail A. Dental caries. Nat Rev Dis Primers. 2017;3:17030.

5. Chu CH, Mei ML, Lo EC. Use of fluorides in dental caries management. Gen Dent. 2010; 58(1):37-43.

6. Hamasha AA, Al Qudah MA, Bataineh AB, Safadi RA. Reasons for third molar teeth extraction in Jordanian adults. J Contemp Dent Pract. 2006; 7(5):88.

7. Desvarieux M, Demmer RT, Rundek T, Boden-Albala B, Jacobs Jr DR, Papapanou PN, Sacco RL. Relationship between periodontal disease, tooth loss, and carotid artery plaque: the Oral Infections and Vascular Disease Epidemiology Study (INVEST). Stroke. 2003; 34(9):2120-5.

8. Meyer MS, Joshipura K, Giovannucci E, Michaud DS. A review of the relationship between tooth loss, periodontal disease, and cancer. Cancer Causes Control. 2008; 19(9):895907.

9. Anil S, Preethanath RS, AlMoharib HS, Kamath KP, Anand PS. Impact of osteoporosis and its treatment on oral health. Am J Med Sci. 2013; 346(5):396-401.

10. Mealey BL, Oates TW. Diabetes mellitus and periodontal diseases. J Periodontol. 2006; 77(8):1289.

11. Kassebaum NJ, Bernabé E, Dahiya M, Bhandari B, Murray CJ, Marcenes W. Global burden of untreated caries: a systematic review and metaregression. J Dent Res. 2015; 94(5):650.
12. Frencken JE, Sharma P, Stenhouse L, Green D, Laverty D, Dietrich T. Global epidemiology of dental caries and severe periodontitis-a comprehensive review. J Clin Periodontol. 2017; 44:S94.

13. Warnakulasuriya S. Global epidemiology of oral and oropharyngeal cancer. Oral Oncol. 2009; 45(4-5):309.

14. Hussein AA, Helder MN, de Visscher JG, Leemans CR, Braakhuis BJ, de Vet HC, Forouzanfar T. Global incidence of oral and oropharynx cancer in patients younger than 45 years versus older patients: A systematic review. Eur J Cancer (Oxford, England: 1990). 2017; 82:115.

15. Alhaddad B, Rózsa NK, Tarján I. Dental trauma in children in Budapest. A retrospective study. Eur J Paediatr Dent. 2019; 20(2):111.

16. Azami-Aghdash S, Azar FE, Azar FP, Rezapour A, MoradiJoo M, Moosavi A, Oskouei SG. Prevalence, etiology, and types of dental trauma in children and adolescents: systematic review and meta-analysis. Med JIslam Repub Iran. 2015; 29(4):234.

17. Khan F, Ayub A, Kibria Z. Knowledge, Attitude and practice about oral health among general population of Peshawar. J Dow Univ Health Sci. 2013;7(3)117-21.

18. Younus A, Qureshi A. Tooth brush changing frequency and associated socio-demographic and oral hygiene factors among residents of Karachi. J Dent Oral Hyg. 2016;8(2):4-11.

19. Ahmed ZU, Shafiq K, Wali A, Siddiqui TM, Usman A. Knowledge, attitude and practices of oral health amongst low socioeconomic strata of Sindh. Pak Oral Dent J. 2016;36(4):628

20. Nagarajappa R, Sahare P, Shukla N, Tuteja J, Bhalla A. Knowledge, attitude and practices regarding oral health among out patients at Rama Dental College, Kanpur. Rama Univ J Dent Sci. 2015;2(1):8-14.

21. Singh A, Gambhir RS, Singh S, Kapoor V, Singh J. Oral health: How much do you know?-A study on knowledge, attitude and practices of patients visiting a North Indian dental school. Eur J Dent. 2014;8(1):63.

22. Kaira LS, Srivastava V, Giri P, Chopra D. Oral Health-Related Knowledge, Attitude and Practice among Nursing Students of Rohilkhand Medical College and Hospital. J Orofac Res. 2012;2(1):20-3.

23. Dawani N, Afaq A, Bilal S. Oral health knowledge, attitude and practices amongst teachers of public school set-up of Karachi, Pakistan. J Dow Univ Health Sci. 2013;7(1):15-9.

24. Kapoor D, Gill S, Singh A, Kaur I, Kapoor P. Oral hygiene awareness and practice amongst patients visiting the department of periodontology at a dental college and hospital in North India. Indian J Dent. 2014;5(2):64.

25. Verma S, Deepak U, Misra N, Saran G, Banerjee A, Jaiswal S. Cleaning Aids in Dentistry: A Cognizant Survey. J Adv Med Dent Sci Res. 2019;7(1):14-6.

26. Goryawala SN, Chavda P, Udhani S, Pathak NV, Pathak S, Ojha R. A survey on oral hygiene methods practiced by patients attending Dentistry Department at a Tertiary Care Hospital from Central Gujarat. J Int Soc Prev Community Dent. 2016;6(2):115.

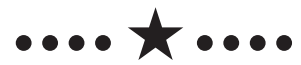

